\title{
TAMBOR, A COMUNICAÇÃO ANCESTRAL: IMAGENS, ESTÉTICAS E RUPTURAS EPISTEMOLÓGICAS EM UMA COMUNIDADE TERREIRA
}

\author{
Olavo Ramalho Marques ${ }^{1}$ \\ Nina Fola ${ }^{2}$
}

\section{Primeiras palavras}

\begin{abstract}
O R'Gongo é uma manifestação de ancestralidade negra que surge como uma festa de Pretos(as) Velhos(as) na Comunidade Ilê Asé Iyemonjá Omi Olodô em 1993 em contraponto ao dia 13 de maio. Como todo ano é temático, neste reverenciaremos Ngoma e homenageamos a ancestralidade de Mestre Borel.
\end{abstract}

Assim constava a descrição contida no material de divulgação do evento em uma página criada para tal finalidade em uma rede social de grande utilização no Brasil na atualidade. O R'Gongo é uma mostra de cultura negra, festa e/ou festival realizada em homenagem ao Vovô Cipriano de Angola, Preto Velho de presença marcante nesta comunidade terreira, cujo centro territorial é o Ilê (ou terreiro) localizado nos altos da Vila São José, bairro popular da região leste de Porto Alegre/RS. Vovô Cipriano de Angola é um Preto Velho - entidade da umbanda que simboliza o espírito de um negro escravizado e muito velho. É entendido como um ancestral que orienta a comunidade, reforçando esses laços a cada ano com a participação na festa em homenagem a ele. $\mathrm{O}$ R'Gongo é a materialização presente de uma festa que o Vovô presenciou em vida, quando escravizado, e relatou para a comunidade. Em sua $17^{\mathrm{a}}$ edição, realizada em maio de 2015, a mostra teve como tema "Tambor, a comunicação ancestral", e as atividade versaram sobre a centralidade do Ngoma (tambor, em língua banto) nas mais diversas manifestações ligadas à cultura de matriz africana: musicalidade, samba de roda, jongo, capoeira, dança afro, celebrações religiosas, entre outras tantas.

Abordamos aqui o R'Gongo a partir de uma experiência de pesquisa e produção compartilhada, mediada pela produção de um registro documental em vídeo sobre a mostra, realizada por solicitação da comunidade ${ }^{3}$. A relação entre pesquisador e comunidade terreira (que conta com seus próprios intelectuais, sendo em parte composta

\footnotetext{
${ }^{1}$ Universidade Federal do Rio Grande do Sul - Campus Litoral Norte, Brasil.

${ }^{2}$ Egbomi da Comunidade Terreira Ile Ase Iyemonja Omi OLodo; OSCIP Africanamente; Universidade Federal do Rio Grande do Sul.

${ }^{3}$ O Documentário encontra-se disponível em: https://www.youtube.com/watch?v=kMqeKUBWkDc
} 
por pesquisadores em cursos de graduação e pós-graduação) remonta ao processo de produção do documentário etnográfico “A Tradição Bará do Mercado" (Direção de Ana Luiza Carvalho da Rocha, 2008) ${ }^{4}$, realizado a partir da demanda da Congregação em Defesa das Religiões Afro-Brasileiras (CEDRAB) em busca do reconhecimento como Patrimônio Imaterial desta tradição que os enraíza ao Mercado Público Central de Porto Alegre. A produção, na qual Olavo R. Marques foi responsável pelo trabalho de campo, se deu através de uma contínua interlocução entre equipe e afrorreligiosos. Baba Diba de Iyemonja, babalorixá da Comunidade Terreira Ilê Asè Iyemonja Omi Olodô, então membro da CEDRAB e interlocutor importante na produção do documentário, foi um dos entrevistados e nos convidou a partilhar e gravar uma festa de Iansã no terreiro. Iniciou-se aí uma interação entre comunidade e pesquisadores que gerou outros produtos como o documentário "Mestre Borel e a ancestralidade Negra em Porto Alegre" (direção de Anelise Guterres e codireção de Baba Diba de Iyemonja, 2010) ${ }^{5}$ e a tese de doutorado "Sobre raízes e redes: territorialidades, memórias e identidades entre populações negras em cidades contemporâneas no sul do Brasil” (Marques, 2013) defendida por Olavo R. Marques junto ao PPGAS/UFRGS.

Em abril de 2015, quando da realização uma banca composta de membros da comunidade para avaliação da referida tese, em processo de revisão para ser lançada como livro, a comunidade convida o pesquisador para a produção de um registro em vídeo do festival de cultura negra do terreiro, que se realizaria no mês seguinte. Deste modo, a partir de uma solicitação feita pelo grupo para que se realizasse o registro do R'Gongo - ligada a uma demanda de memória e de circulação da intensa produção cultural pela comunidade do terreiro, através de imagens - as escolhas de gravação, edição, montagem e divulgação do vídeo foram construídas em conjunto entre

\footnotetext{
4 "Os caminhos invisíveis do negro em Porto Alegre: A tradição do Bará do Mercado", 2008. Realização: Secretaria Municipal da Cultura de Porto Alegre e CEDRAB-RS; Apoio: Banco de Imagens e Efeitos Visuais/PPGAS/UFRGS; Roteiro de Ana Luiza Carvalho da Rocha e Rafael Devos; Produzido por Anelise Guterres; Antropólogo de Campo Olavo Ramalho Marques; Editado por Alfredo Barros; Direção de Fotografia de Rafael Devos; Som Direto de Viviane Vedana; Direção de Ana Luiza Carvalho da Rocha. O Documentário encontra-se disponível no canal do Banco de Imagens e Efeitos Visuais no site Vimeo: https://vimeo.com/66084028.

${ }^{5}$ Mestre Borel e a ancestralidade negra em Porto Alegre", 2010. Financiado pelo Fumproarte (Prefeitura Municipal de Porto Alegre). Direção: Anelise Guterres; Co-Direção: Baba Diba de Iyemonja; Roteiro e pesquisa: Ana Luiza Carvalho da Rocha; Edição e Direção de Fotografia: Rafael Devos; Assistência de Edição: Guilherme Deporte; Fotografia: Olavo Ramalho Marques; Som Direto e Paisagem Sonora: Viviane Vedana; Produção Executiva: Anelise Guterres; Assistência de Produção: Inara Moraes dos Santos; Design Gráfico: Malu Rocha. O Documentário encontra-se disponível no canal do Banco de Imagens e Efeitos Visuais no site Vimeo: https://vimeo.com/66084028.
} 
pesquisador e comunidade - destacando-se, na interlocução, Baba Diba, Nina Fola e Luana Emil - Oyá Gbemi (mestre em Antropologia Social pelo PPGAS/UFRGS).

O marco de produção do vídeo insere-se na investigação etnográfica sobre dinâmicas territoriais e processos identitários entre populações negras em cidades do Rio Grande do Sul. Neste contexto, através da mobilização de práticas, memórias e sentidos de territorialidade, grupos sociais buscam afirmar identidades, visibilidade e direitos. Mais do que mero instrumento de negociação em campo, a mobilização de recursos audiovisuais nesta pesquisa envolve um claro e manifesto desejo de produção e circulação de imagens por parte do próprio grupo, constituindo-se como canal de diálogo e interlocução, instrumento de produção de representações entre pesquisador e comunidades, propiciando a emergência das imagens de si e dos outros neste jogo interativo. Para além disso, entende-se que o registro de imagens constrói uma possibilidade de interlocução interna na comunidade na perspectiva da autoimagem. $\mathrm{O}$ que queremos dizer, em outras palavras, é que se auto visualizar em imagens, frente à massa de imagens "pasteurizadas" criadas pela TV, é simbolicamente transformador a respeito da construção coletiva de autoestima, item das subjetividades muito caro para a busca de combate ao racismo, mote principal desta comunidade.

A mirada conjunta sobre a mostra e as imagens dela resultantes retrata um momento de celebração e reflexão da comunidade sobre sua cultura, suas tradições e seu lugar no mundo, sua cosmopolítica. O grupo se revela ao espectador, através do potencial interpretativo-narrativo dos recursos audiovisuais, em suas feições estéticas, sua corporeidade, sua musicalidade, suas sociabilidades e sua espiritualidade.

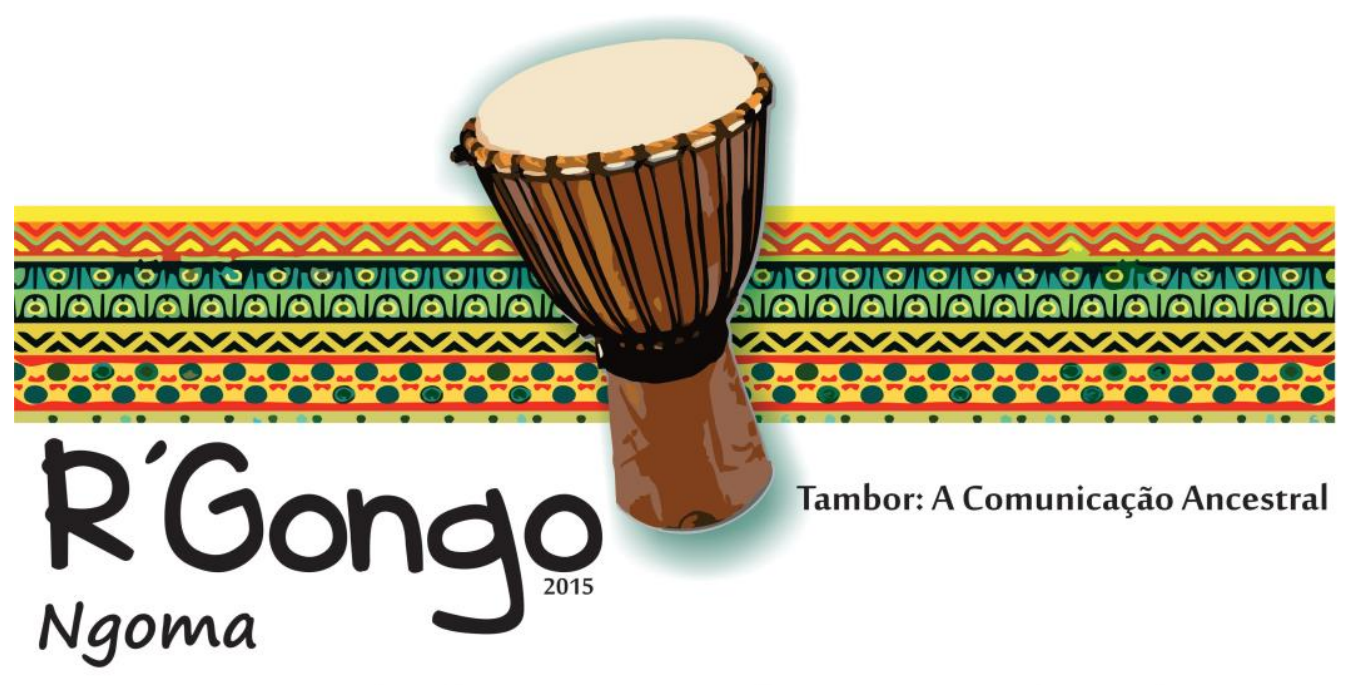

XVII Mostra de Cultura Negra e Festa do Vovô Cipriano de Angola 
O R'Gongo, em sua $17^{\text {a }}$ edição, foi realizado ao longo dos dias, 21, 22 e 23 de maio de 2015, as atividades iniciando à tarde e se estendendo até a noite. Como mostra cultural, agregou apresentações musicais, esquetes teatrais, apresentações de dança afro, samba de roda, jongo e roda de capoeira, performatizadas por diferentes grupos da própria comunidade e também por convidados "de fora" - alguns dos quais com participação de membros da comunidade. Apresentaram-se: Grupo Ìbejì, Mestre Jaburu, Áfricanamente Capoeira Angola, Grupo de Jovens do Projeto Awon Omode, Pingo Borel e Auristela Mello, Grupo Olodô, Coral do CECUNE (Centro Ecumênico de Cultura Negra). Outros grupos da comunidade também se fizeram presentes, grupos estes que não necessariamente tinham um nome, cujo nome foi trocado ou mesmo esquecido, em meio à enorme produção cultural por parte de pessoas da comunidade, dentro e fora do terreiro, em seus muitos subgrupos, feitos, refeitos e desfeitos conforme sua dinâmica vital.

O evento, em seu último dia, culminou com uma sessão de pretos e pretas velhas, a Festa do Vovô Cipriano de Angola, momento em que a entidade homenageada se fez presente, espiritual e corporalmente junto à comunidade, dançando, ouvindo os pontos a ele oferecidos pelos alabês e cantados em coro pelos participantes, sendo agraciado com apresentações artísticas, homenagens e presentes, falando com seu povo e confraternizando com outros muitos pretos e pretas velhas que vêm ao mundo dos homens neste momento de sacralização do cotidiano (Pólvora, 1994). Uma das participantes da festa comenta, em certo momento: "é impressionante como os nossos jovens estão cada vez mais recebendo vovôs". Comentário importante porque pretos e pretas velhas representam a ancestralidade e os elos com saberes imemoriais por eles perpetuados.

Todas as atividades que compuseram o R'Gongo 2015 são convergentes quanto à exposição conjunta de feições que compõem a cultura de matriz africana, em termos de uma diversidade de produções artísticas que versam a partir de uma mesma estética. Uma corporeidade especifica, territorializada pela sonoridade, pelo ritmo pulsante do tambor, couro animal rufando sob o toque das mãos dos alabês ou tamboreiros. Como o evento tematizava, ali estava expressa a centralidade do Ngoma em todas as manifestações dessa cultura. 
A importância da alimentação na cultura de matriz africana também ganhou destaque: uma banca improvisada oferecia acarajé recheado e cocada para os participantes, enquanto cada um dos dias do evento foi marcado pelo consumo comunitário de um prato específico, como feijoada e moqueca de peixe.
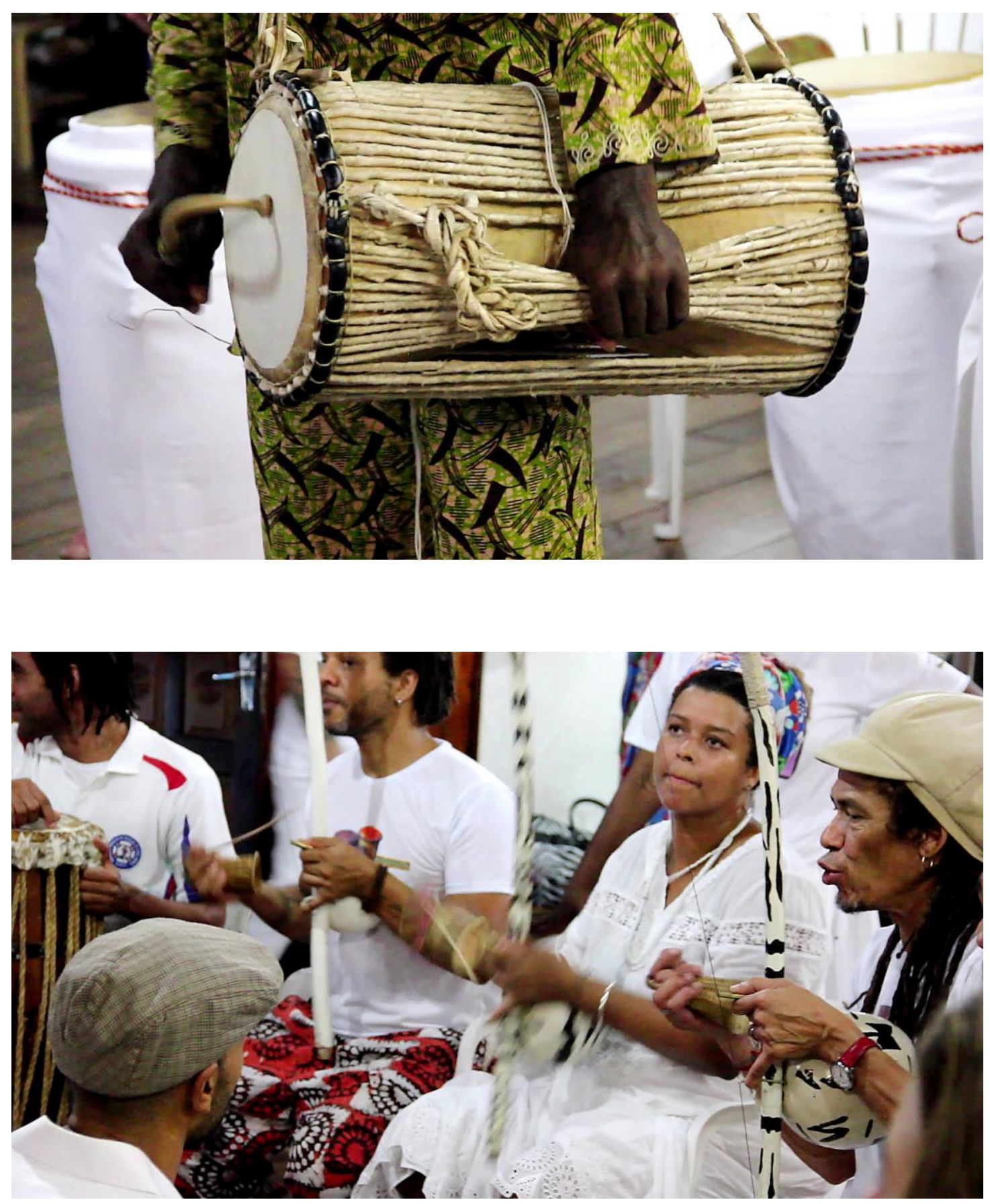

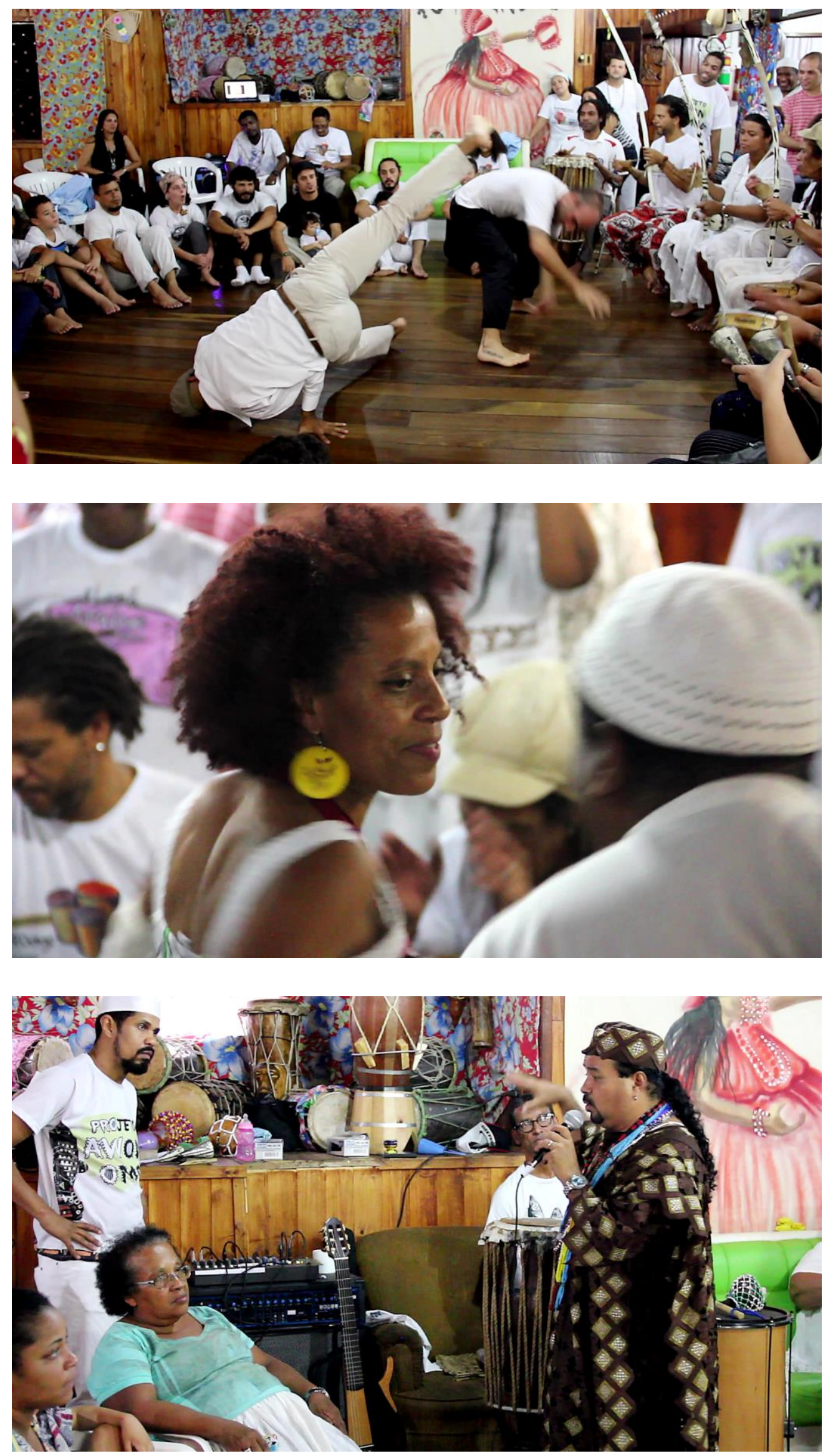


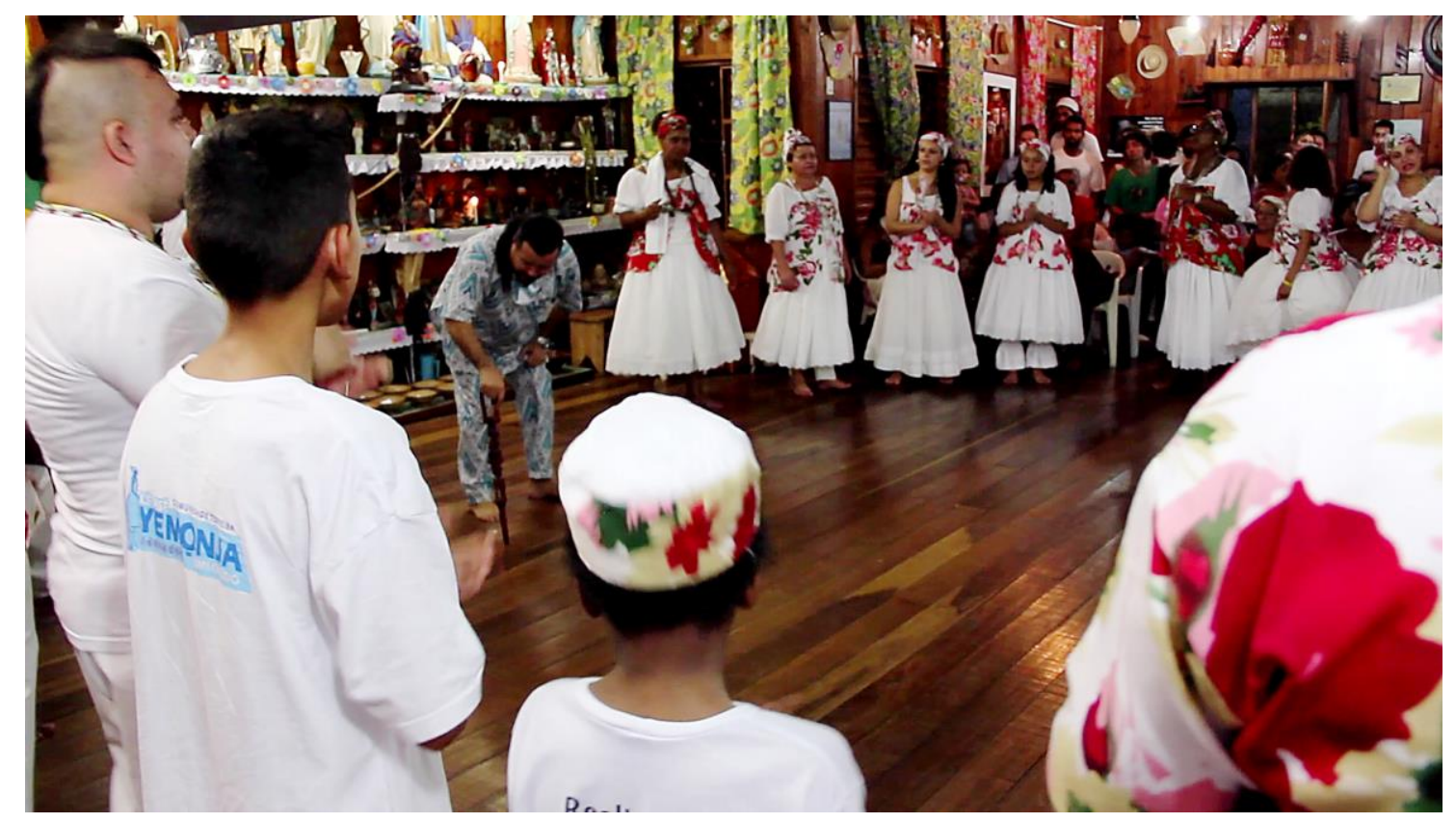

O R'Gongo 2015 foi um evento que homenageou Mestre Borel, descrito por Nina Fola, em sua fala de abertura do festival, como "nosso maior expoente", "Sangoma, aquele que toca o Ngoma, o tambor". Mestre Borel foi uma figura de presença constante, em espiritualidade e imagem: personificado em um painel posicionado em uma parede ao fundo do Salão, com um retrato seu e os dizeres "Mestre Borel: Ancestralidade Afrogaúcha, Babalorisá e Alagbe. A comunidade do batuque lhe reverencia e agradece". Uma das homenagens a Borel foi a exibição do documentário etnobiográfico "Mestre Borel e a Ancestralidade negra em Porto Alegre". Representado em imagens (fotografias, textos, vídeos e falas), teve seu legado ali presentificado em seus filhos: Mestre jaburu, conduzindo as rodas de capoeira e samba de roda, Pingo Borel e Auristela Mello, tocando tambor e entoando rezas e pontos.

$\mathrm{Na}$ operação da câmera ao registrar o evento, alguns indícios dessa contínua sobreposição de temporalidades em um terreiro se fizeram presentes. Baba Diba apresenta e anuncia a exibição do documentário sobre Mestre Borel, dizendo ter sido um sonho realizado: "a gente fez grandes passeios com Mestre Borel, mas também passeou na vida e no passado dele. Ele fez a gente ter saudade de um tempo em que a gente não viveu". Neste momento, a câmera mostra a tela branca ainda inerte, quando o som de batidas de tambor suscita no expectador a dúvida sobre sua origem, já que tanto tambor vinha sendo tocado no evento; a imagem do projetor surge na tela e vai sendo aos poucos ajustada. Quem toca é Borel. Uma imagem seguinte mostra Borel 
caminhando em direção e depois dentro do Mercado Público de Porto Alegre; à imagem da tela sobrepõem-se os corpos daqueles que caminham no terreiro, em sua sociabilidade calorosa, ruidosa e inquieta. Uma imagem que encarna a sobreposição de tempos sintetizados em mesmo gesto: caminhar. Coincidentemente - ou sincronicamente? - trata-se de um plano do documentário em que Olavo Marques caminha ao lado de Borel na entrada do mercado.

O vídeo registrado a partir do evento, editado em sua versão inicial, foi exibido no R'Gongo 2016, em primeira mão, como um presente ao Vovô Cipriano - e, por extensão, à comunidade terreira como um todo. $\mathrm{O}$ fato de se ter registrado uma sessão de Pretos Velhos, de o vídeo ter sido apresentado como um presente ao Vovô Cipriano, conduz a uma discussão extremamente interessante quanto às entidades que podem ou não ser registradas "no mundo". No complexo do chamado Batuque Gaúcho, existe um interdito quanto ao registro em imagens dos Orixás "no mundo", quando ocupam os corpos dos afrorreligiosos. Esta interdição se justifica pelo fato de a pessoa ocupada não saber ou não ter consciência sobre o fato de que ela é ocupada pelo orixá, sob pena de "ficar louca". Tal interdito, entretanto, não se verifica entre os exus e nem entre os pretos velhos. Os "vovôs", ao contrário dos Orixás, podem ser fotografados e filmados, como fica evidente pela profusão de câmeras e celulares de participantes registrando a sessão. No caso de Vovô Cipriano de Angola, a entidade não só permite como demanda este registro, aceitando-o como um presente, no caso da produção aqui em questão.

As entidades, como vimos, tem uma imensa força de orientação na ação dos vivos em meio à comunidade terreira. Inclusive quanto à possibilidade de realização de pesquisas, ao que dizer e o que não dizer (e para quem), àqueles que estão ou não autorizados a dizer o que pode ser dito, aos limites da abertura no que tange ao que mostrar, como mostrar, até onde mostrar, em meio aos saberes, práticas e segredos da religião. Em nosso caso específico, as entidades orientam e delimitam o que registrar e o que não registrar em imagens: até que altura do ritual se pode registrar, quais as entidades que se permitem registrar e quando, as formas de circulação dessas imagens. Estas imagens, como representações dos seres - pessoas e entidades - em suas relações, são sempre pensadas em meio à multiplicidade da concepção de pessoa nas religiões de matriz africana, em seus entrecruzamentos com orixás, exus, ancestrais, espíritos. 
O mais importante a recapitular aqui é o fato de que o R'Gongo, para além desta importante discussão acerca das representações das pessoas e entidades em imagens, busca proporcionar um momento de reflexão da comunidade sobre seu lugar no mundo. Como descrito no início do evento, trata-se de um contraponto ao dia 13 de maio, data de celebração da abolição da escravatura no Brasil. Ou seja, uma contraposição às representações correntes no que diz respeito à escravidão, sua abolição e as relações raciais desde aí tecidas. Registrar o evento implica em perpetuar a memória desta reflexão e dar visibilidade a ela, ampliando o seu alcance. De uma celebração da comunidade para a comunidade, temos, talvez, uma abertura da comunidade para os outros.

Nesses termos, podemos pensar no R'Gongo e sua narrativa em termos das perspectivas pós-coloniais e descoloniais. Como propôs Homi Bhabha (1998), movimentos e grupos sociais, com suas temporalidades peculiares que desafiam as narrativas dominantes enraizadas nas formas hegemônicas de imaginar a nação, ao agir, constituem outras narrativas - às quais o autor denomina performáticas - que possuem como objetivo inscrever nas narrativas pedagógicas outras histórias. Esses discursos das etnicidades emergentes, propôs, configuram-se como um espaço suplementar de significação cultural, um discurso minoritário que antagoniza generalizações e homogeneidades na história da nação e agregam a ela. Esses "outros" se inscrevem através da performance e da agência, evidenciado conflitos e antagonismos no seio da coletividade. Os movimentos étnicos podem ser pensados, assim, como uma emergente temporalidade disjuntiva nos discursos da unidade nacional mestiça. Nesses termos, ainda de acordo com Bhabha, à medida que a identidade cultural e política são sempre construídas na alteridade, a contra-modernidade pós-colonial vem trazer à tona outras subjetividades, forjadas a partir de experiências históricas e lugares de significação diversos, sustentadas por outros signos.

No caso do R'Gongo, discutir e desestabilizar as bases das narrativas e representações sobre a escravidão é pensar no Brasil (e na América como um todo) a partir da diáspora e de suas bases culturais africanas, remontando à imensa massa de escravos africanos trazidos para o outro lado do Atlântico como núcleo fundamental das vantagens econômicas na administração colonial - a que James Clifford (1999) chega a definir como um dos elementos da pré-história do pós-colonialismo. As velhas e novas diásporas somadas, aponta Clifford, oferecem material interessante para a análise do 
que denominou como pós-colonialismos emergentes. Os discursos diaspóricos, para o autor, estão entre os principais idiomas das novas formações pós-coloniais, incorporados à emergência de novas comunidades e novos futuros imaginados, pautados por outras concepções, que não as ocidentais, sobre cosmopolitismo, etnicidade e nacionalismo. Por fim, como apontou José Carlos dos Anjos (2006: 23), em sua cosmopolítica de recusa à fusão em uma identidade mestiça totalizadora, "o terreiro faz das raças e das nações um patrimônio simbólico, espaços para percursos nômades, desessencializados".

\section{Rupturas epistemológicas, Antropologia Visual e produção compartilhada}

De acordo com Rocha (1999), a imagem é "instrumento de produção de conhecimento sobre o mundo", ato reflexivo sobre a realidade construído a partir de um enquadramento das feições sensíveis e sensoriais dos fenômenos culturais. Para a autora, na pesquisa etnográfica, não há como nos furtarmos ao registro e narração das experiências partilhadas entre pesquisadores e comunidades, sendo a realidade deste encontro sempre abordada através do entrecruzamento de pontos de vista - no que Gadamer definiu, numa metáfora feliz em sua hermenêutica, como fusão de horizontes. O material imagético oriundo do trabalho de campo constitui a memória de uma relação entre pessoas, um patrimônio que resgata essa experiência temporal de diálogo (Rocha e Eckert, 2015) repleto de representações sobre pessoas e suas culturas em um mundo eternamente em mudança. Para as autoras (2015: 31),

A produção etnográfica, no advento da pós-modernidade, e a construção de novos experimentos etnográficos tem privilegiado a construção de imagens e a perspectiva conceitual da imagem dialética, como preconizava Walter Benjamin (1994), no processo etnográfico em seu potencial imagético.

Pautados pela perspectiva de Jean Rouch (1979), rompemos com a pretensão de isenção e objetividade através do emprego dos recursos audiovisuais e abrimo-nos ao papel da visão subjetiva e subversiva da câmera, instrumento que descortina uma realidade que só através dela se vê. A "câmera participante" na etnografia é uma câmera viva, que sai da imobilidade e entra em transe em conjunto com o grupo que retrata, configurando-se como mediação no processo dialógico do trabalho campo. Assim buscou-se construir a memória do R'Gongo. 
A seleção dos dados e das formas de narrar passam por camadas de leituras, organização e encadeamento de situações etnográficas, enredadas de modo a dar forma à narrativa. Quando tais processos são partilhados entre pesquisadores e comunidades, produzir imagens esteticamente belas não é mero capricho, mas, conforme Jean Arlaud ${ }^{6}$, parte de uma orientação epistemológica que não separa ética e estética, ao conduzir-se pelo desejo de que o grupo se sinta representado na produção que resulta desta composição de olhares. Reflete-se, assim, sobre a produção de imagens como recurso de amplificação do alcance desses rituais, sociabilidades e estéticas escolhidos pelos grupos como elementos de demarcação de territorialidades, afirmação de identidades e busca de visibilidade.

Nos propomos aqui a refletir sobre o R'Gongo a partir da interação de pesquisa mediada pela produção audiovisual. Trata-se, como aponta Claudine de France (2000: 20), de pensar o "desdobramento de um rito cerimonial coletivo de tradição oral durante o qual, por intermédio das imagens, alguns seres humanos mostram-se, ou mostram seres humanos a outros seres humanos". Não pretendemos necessariamente aqui aderir à proposta da autora quanto à Antropologia Fílmica como uma disciplina autônoma, mas, sobretudo, adentrar na proposta de uma análise deste "duplo objeto": o homem e a imagem do homem, o duplo jogo entre a apreensão do sensível e a reflexão sobre esta apreensão. É isto o que nos move. Sobretudo no que diz respeito à comunidade, em termos das relações entre sua autoimagem e suas auto-representações.

Escrever/falar sobre a produção audiovisual, como processo de produção de conhecimento em antropologia, passa por pensar na câmera como instrumento de interação, objeto dotado de grande importância em termos de agência, quando inserido em uma relação dialógica de pesquisa. Em diversas ocasiões, na atualidade - e durante o R'Gongo isso se confirma - temos muitas pessoas registrando os acontecimentos especialmente aqueles considerados "excepcionais" - com suas câmeras e seus abundantes dispositivos móveis. Pesquisadores produzindo imagens encontram-se então em uma situação de "maior liberdade" e menor desconforto provocado pelo portar a câmera e olhar através dela a interação com as outras pessoas em cena. Mas isso não significa, nem de longe, uma menor preocupação com as questões éticas, que se mantém centrais e demandam uma ainda maior vigilância epistemológica.

\footnotetext{
${ }^{6}$ O cinema é como uma dança. Entrevista com Jean Arlaud, cineasta e antropólogo. Realização: Rafael Devos, Olavo Marques, Ana Luiza Carvalho da Rocha, Cornelia Eckert, João Castelo Branco, Peri Carvalho, Flávio Abreu da Silveira. Produção: Banco de Imagens e Efeitos Visuais/Núcleo de Antropologia Visual, 2004.
} 
A necessidade de ruptura com uma cultura visual hegemônica, dominada e determinada pelo mass media, as linguagens cinematográficas e televisivas de fácil absorção e orientadas para o mercado acompanham a antropologia visual há muitas décadas. As discussões a respeito da colonialidade da própria epistemologia científica de raízes iluministas, nos últimos tempos, conduzem a uma nova vigilância em termos das narrativas produzidas em nossa pesquisas no seio das linhagens disciplinares da antropologia. A crescente presença de abordagens e produções participativas, compartilhadas e comunitárias certamente vem enriquecendo olhares, escutas, narrativas e sensibilidades. Enriquece também o debate epistemológico quanto à necessidade da descolonização da própria produção de conhecimento em ciências sociais.

A realização do R'Gongo responde à urgência de uma agenda de pensamento descolonial em meio à comunidade terreira: questionar os valores dominantes de uma sociedade racista que carrega um legado escravocrata entranhado em suas relações simbólicas mais profundas. A produção e a reflexão sobre a produção de imagens do evento, como momento dramático de performatização do ser comunidade e sua posterior exibição de forma mais ampla, como que disponibiliza uma perspectiva crítica deste próprio grupo, em seus processos de construção de conhecimento.

Em termos das escolhas para a produção do vídeo, optamos pela não realização de entrevistas, de modo a construirmos a narrativa pela estética, ritmo e oralidade do próprio grupo no evento - enquanto complexo ritual. Do mesmo modo, não incorporarmos narração em off na produção final. Trata-se de uma produção visual experimental e "caseira". Neste caso, realizada a partir de um "olhar caseiro" dentro de uma casa de religião, ilê ou terreiro. Coproduzida na interlocução, com dialogo constante na mediação da moldagem do filme. Com um tempo/ritmo muito peculiar em sua produção. A participação da comunidade, de parte ou de pessoas dela, certamente acrescenta legitimidade à produção final do processo, como documentário em que a comunidade possa se reconhecer, "endossar" ou "encampar" este produto da relação de pesquisa como expressão de si. Esta legitimação é importante. Mas a natureza da produção compartilhada, acreditamos, vai além dela, abrindo-se para uma perspectiva do narrar junto, partilhando escolhas do grupo/comunidade, mediadas pela interlocução contínua, para contar as histórias. 
Buscamos uma aproximação do R'Gongo que se pautasse pelas próprias formas de sociabilidade do terreiro, conduzindo o expectador a uma imersão neste território comunitário. Tanto quanto possível, pelo tato, à pele, por dentro, leva-lo a sair da imobilidade e mergulhar no ritmo dos tambores. Nesses termos, a escolha durante a construção partilhada do roteiro de edição foi por uma montagem "linear", quase cronológica - seguindo o desejo do grupo do que mostrar no vídeo, de modo que se desse a produção de um retrato da diversidade que abarcou o R'Gongo, seus muitos personagens e suas riquezas culturais. Nesta montagem linear, entretanto, o ritmo é buscado no próprio tambor - o mote que encadeia tudo o que compõe o R'Gongo em sua edição em 2015. Se a narrativa é também rítmica, a opção foi por uma montagem a partir do som, das frases do tambor - enquanto comunicação, como nos dizia Borel. O grande desafio desta montagem foi imprimir um caráter de continuidade fluida, não truncada, através dos cortes entre planos. E em tais cortes, a continuidade do ritmo do tambor entra sempre em cena.

É interessante a reflexão acerca das dimensões sonoras das imagens e representações. Quando falamos em ressonância, reverberação, eco, ideias recorrentemente acionadas quando o tema é memória, empregamos poderosas metáforas sonoras. Como pontuam Rocha e Eckert (2015: 29), "é através da evocação das imagens na luta contra o esquecimento que teóricos da Imagem, como Walter Benjamin defendeu (Benjamin, 1993), abordam sua qualidade ética que reverbera na memória”. O som e ritmo dos tambores, nas expressões culturais de matriz africana, anunciam-se permanentemente a partir de uma conexão profunda com a vibração da memória. Como nos ensinou Mestre Borel, o rufar do couro animal, entoado como mensagem, evoca a ancestralidade ${ }^{7}$. Foi o que buscamos perpetuar na construção do vídeo, como memória de um evento que celebra a centralidade do tambor neste universo simbólico.

Para produzir estas discussões sobre o processo de construção destas memórias, buscamos, aqui, uma escrita também experimental e partilhada. Trata-se de um produto em hipermídia: este texto e o vídeo produzido fazem parte de uma mesma construção reflexiva, que busca o diálogo entre sujeitos, mas também entre linguagens. Este artigo busca concretizar a reflexão conjunta, entre pesquisador/antropólogo visual e

\footnotetext{
${ }^{7}$ Esta discussão complexa extrapola o espaço textual deste artigo. Aponta, entretanto, direções interessantes para produção futuras.
} 
pesquisadora/membro da comunidade, sobre o processo de produção de uma memória visual do R'Gongo de $2015^{8}$.

Produzir em conjunto as imagens, narrativas e escritas conceituais nos conduz a pensar sobre as delimitações entre o ser/estar perto, dentro, longe e/ou fora dos grupos e comunidades. Escrever este ensaio desde o início nos conduz a desafiar estas fronteiras. As experiências de produção compartilhada, tão discutidas no âmbito da antropologia visual, precisam ser discutidas no âmbito da antropologia como um todo. Aliás, vem sendo discutidas, ao menos desde o questionamento da autoridade etnográfica pelos pós-modernos, tal qual enunciou Clifford (2002), e ganham em radicalidade com as tendências perspectivistas.

Jean Rouch, entretanto, vinha fazendo este movimento desde os anos 50, enquanto a tendência dominante em antropologia era o estudo das "sociedades sem Estado" de inspiração estrutural-funcionalista. Em linguagem cinematográfica. Pouco em linguagem escrita. Talvez por isto sua "pequena penetração" nos meandros da antropologia mais orientada pelos "rigores acadêmicos" - evidentemente iconoclasta, imersa que estava em sua tradição livresca. Isso conduz a pensar a respeito do porquê e como a produção cinematográfica em etnografia - ou pesquisa etnocinematográfica, como costumava definir Jean Arlaud ${ }^{9}$ - muitas vezes antecipa profundas reflexões e mesmo crises epistemológicas que invadirão a antropologia como campo de conhecimento científico. Talvez porque a natureza polissêmica, o sentido aberto a múltiplas interpretações e o caráter necessariamente narrativo da pesquisa com imagens conduzem a um pensar a produção resultante do encontro e da interlocução etnográfica em outros termos. Ao que sabemos, Jean Rouch convidava seus interlocutores ou era por eles interpelado nos termos: "vamos fazer um filme?" Isso conduzia a um pensamento comum, de contar as histórias dessas pessoas e do seu universo vivido. Contar a história do R'Gongo 2015 partilha deste espírito, na medida em que a comunidade convida o antropólogo visual a produzir a memória do evento, e posteriormente o antropólogo convida uma interlocutora importante a produzir este artigo, como reflexão sobre todo o processo de produção imagética e narrativa em vídeo.

\footnotetext{
${ }^{8}$ A escrita conjunta e experimental de um ensaio sobre este processo comporta, como não poderia ser diferente, algumas soluções que encontramos para enfrentar os desafios de uma construção "a quatro mãos", a partir de olhares e lugares ora distintos, ora convergentes, sobre as questões aqui enquadradas, no espaço de um artigo.

${ }^{9}$ Idem
} 
Deleuze (2005) apresenta uma interessante discussão sobre o fato de o plano (imagem-movimento) ser uma imagem que está necessariamente no presente - de forma muito evidente no chamado cinema direto e ainda mais como instrumento de linguagem documental em antropologia. Entretanto, como aponta o autor, "cada presente coexiste com um passado e um futuro sem os quais ele próprio não passaria. Compete ao cinema apreender o passado e o futuro que coexistem com a imagem presente. Filmar o que está antes e o que está depois..." (2005: 52, grifo do autor).

Pensar sobre os encadeamentos temporais do R'Gongo nos inclina a refletir sobre pesquisa junto ao evento, enquanto "presente etnográfico", de um lado, e a própria realização do evento, por parte da comunidade, de outro. Os desdobramentos, entretanto, são múltiplos, e nos conduzem à contínua evocação do passado, nos termos do asè da ancestralidade, sempre presente, inclusive nos corpos dos religiosos. À presença imemorial do continente africano, imaginado e performatizado. À memória do evento a partir do registro imagético - visual e sonoro - demandado pela comunidade e mediado pelo olhar-escuta e mise-en-cene do pesquisador, imbuído pelos dispositivos técnicos de registro. $\mathrm{E}$ ao posterior encadeamento narrativo das imagens produzidas na edição do material gravado.

Deste modo, a montagem linear (cronológica) que resume o tempo de evento no tempo diegético (trinta minutos acordados entre Olavo e Nina na construção do roteiro), não implica em uma necessária linearidade do tempo. Se cada plano contém em si uma exploração do tempo, em alguns momentos esse tempo ganha relevo e espessura (em que buscou-se a força do tempo sintetizada em imagem). Em realidade, mostrar o presente do evento é expandir camadas de tempo, sobretudo quando se trata de uma forma cultural em que a presença contínua da ancestralidade marca de forma tão evidente a sobreposição temporal - o passado que se distende sobre o presente e anuncia futuros.

O R'Gongo, como evento complexo, reflete sobre as relações tais quais estabelecidas, e projeta novas formas em um futuro almejado de reflexividade, consciência, empoderamento - forjando novas narrativas. 


\section{Reflexão final - O R'Gongo e a cultura negra em Porto Alegre, no Brasil}

A matriz afro é forjada numa ruptura - a escravidão. De outra forma, esta ruptura pode ser interpretada como a abertura para uma diáspora africana e territorialização de afrodescendentes em toda as Américas, como apontou Gilroy (2002). Nesses termos, tal ruptura não é decisiva, mas projetou uma série de continuidades e perpetuações. Como mostraram Pierre Verger (1997: 23), Roger Bastide (1973) e outros pesquisadores, a persistência das religiões de origem africana foi uma consequência imprevista do tráfico de escravos da África às Américas, constituindo-se como campo de extraordinária resistência cultural. A centralidade da ancestralidade em diversas manifestações da cultura de matriz africana torna isso explícito. A permanente orientação à tradição - aos velhos e seus ensinamentos, aos fundamentos - implica um permanente retorno e reatualização do passado.

O R'Gongo, para a Comunidade Terreiro, materializa esta resistência negra e social e comunitária. Esta necessidade de entender-se e encontrar humanidade, referência de vida, subsistência e sentidos à partir de uma louvação ao ancestral por Vovô simbolizado. Ele é silenciosamente ouvido e seguido. Suas palavras organizam e confortam. E, dentro deste panorama, passado e presente se justificam, imaterializando o tempo e as vivências.

África há séculos, metonimicamente, está aqui.

\section{Referências}

ANJOS, José Carlos dos. No território da linha cruzada: a Cosmopolítica afro-brasileira. Porto Alegre: UFRGS/Fundação Cultural Palmares, 2006.

BASTIDE, Roger. Estudos afro-brasileiros. São Paulo: Editora Perspectiva, 1973.

BENJAMIN, Walter. Magia e técnica, arte e política. Ensaios sobre Literatura e História da Cultura. São Paulo: Brasiliense, 1993.

BHABHA, Homi. O local da cultura. Belo Horizonte, Ed. UFMG, 1998.

CLIFFORD, James. A experiência etnográfica: Antropologia e Literatura no século XX. Rio de Janeiro: UFRJ, 2002.

. "Las diásporas". In: Itinerarios transculturales. Barcelona, Gedisa, 1999, p. 299-339.

DELEUZE, Gilles. Cinema 2 - A imagem-tempo. São Paulo: Brasiliense, 2005.

FRANCE, Claudine. Antropologia fílmica - uma gênese difícil, mas promissora. In: Do filme etnográfico à antropologia Fílmica. Campinas: Unicamp, 2000. p. 17-42.

GILROY, Paul. O Atlântico Negro: modernidade e dupla consciência. Rio de Janeiro: 34/Universidade Cândido Mendes, 2002.

MARQUES, Olavo Ramalho. Sobre raízes e redes: territorialidades, memórias e identidades entre populações negras em cidades contemporâneas no sul do Brasil. Tese (Doutorado em antropologia) - Programa de Pós-Graduação em Antropologia Social/Instituto de Filosofia e Ciências Humanas, Universidade Federal do Rio Grande do Sul, 2013. 
PÓLVORA, Jaqueline B. A sagração do cotidiano: estudo sobre a sociabilidade em um grupo de batuqueiros de Porto Alegre/RS. Dissertação (Mestrado em Antropologia Social) - Programa de Pós-Graduação em Antropologia Social/Instituto de Filosofia e Ciências Humanas, Universidade Federal do Rio Grande do Sul, Porto Alegre, 1994.

ROCHA, Ana Luiza Carvalho da e ECKERT, Cornelia. A preeminência da imagem e do imaginário nos jogos da memória coletiva em coleções etnográficas. Brasília: ABA, 2015. . O tempo e a cidade. Porto Alegre: UFRGS, 2005.

ROCHA, Ana Luiza Carvalho da. Antropologia visual, um convite à exploração de encruzilhadas conceituais. In: ECKERT, Cornelia e MONTE MOR, Patrícia. Imagem em Foco, novas perspectivas em antropologia. Porto Alegre: UFRGS, 1999. p. 55-83.

ROUCH, Jean. La caméra et les hommes. In: FRANCE, Claudine (org.). Pour une anthropologie visuelle. Paris: Mouton, 1979. p. 53-71.

VERGER, Pierre Fatumbi. Orixás, deuses iorubas na África e no Novo Mundo. Salvador: Corrupio, 1997.

Recebido em: 30/01/2017. Aprovado em: 21/03/2017. 